\title{
La perspectiva de género en la política estatal: impactos y desafíos
}

\section{- Juan Marco Vaggione \\ Universidad Nacional de Córdoba/Conicet}

De formas obvias o sutiles, en las calles o en las casas, los movimientos feministas y LGBTQI cambiaron los modos de concebir y habitar el mundo. Estos cambios visibilizaron desigualdades y exclusiones generadas por un orden heteropatriarcal con el que convivimos por siglos; politizaron las violencias contra las mujeres, violencias agazapadas en secretos y complicidades colectivas; evidenciaron la homo/transfobia a través de testimonios y datos. A su vez, estos movimientos resignificaron y ampliaron los límites para el encuentro, para comprender y expandir el deseo y el placer como parte de la política. Los cambios logrados también fueron el resultado de fiestas, bailes y música; de activar la alegría y la complicidad en búsqueda de mundos más igualitarios.

Algunos de estos múltiples cambios se fueron condensando en la denominada "perspectiva de género" en tanto categoría analítica y directriz para las políticas estatales. No sin tensiones, resistencias y limitaciones, esta perspectiva comenzó a incorporarse en las legislaciones y en las políticas públicas como estrategia para visibilizar y revertir las desigualdades y exclusiones generadas por el heteropatriarcado. El debate sobre la reforma del Poder Judicial es otro ejemplo de la importancia (y necesidad) de la perspectiva de género para confrontar, entre otras, la discriminación vertical y horizontal de las mujeres en los órganos encargados de impartir justicia. Este proyecto incluye expresamente esta perspectiva en su articulado y afirma que deberá respetarse la diversidad de géneros en la selección de magistradxs (art. 16) y que la perspectiva de género debe ser un aspecto a valorar en la selección de lxs candidatxs (art. 37). Si bien más de la mitad de lxs integrantes del Poder Judicial son mujeres, su presencia se reduce dramáticamente cuando se consideran los cargos de mayor jerarquía.

El principal objetivo de esta contribución es considerar la consolidación de la perspectiva de género como parte de un proceso de demoralización de las políticas estatales profundizado por los movimientos feministas y LGBTQI. Además, nos interesa marcar algunos desafíos actuales para esta perspectiva que emergen, precisamente, de la relevancia e institucionalización que adquirió en la región.

\section{De-moralizar al derecho}

Los movimientos feministas y LGBTQI urdieron estrategias y argumentos legales que sedimentaron la importancia (y la urgencia) de una reforma estructural no solo en las formas de administrar la justicia sino, incluso, de definirla. Estos movimientos 
lograron corporizar el derecho; trajeron al debate de lo legal mucho de aquello que, invisibilizado, lo saturaba. En cruce con el marxismo, con los estudios poscoloniales o, incluso, con el liberalismo, los feminismos y sectores LGBTQI le imprimieron una nueva impronta al derecho transformándolo en uno de los principales instrumentos, y también arena, para lograr sociedades más justas e igualitarias, más felices y libres.

En sus múltiples diálogos y tensiones, los feminismos y los sectores LGBTQI lograron politizar las formas en que el derecho recogía, protegía (e invisibilizaba) una construcción hipermoralizada del orden sexo-género que obedece, al menos en América Latina, al impacto del catolicismo. Demoralizar el derecho, destilarlo de la moral católica, fue y es uno de los principales desafíos para lograr marcos regulatorios y políticas públicas inclusivas y democráticas. No es infrecuente que en aquellos contextos donde primó una religión mayoritaria, como el catolicismo en la región, se haya producido un proceso de transmutación y reinscripción de lo religioso como parte de la cultura, de la ley y la moral de los países (Jakobsen y Pellegrini, 2004; Beaman, 2013).

Demoralizar no significa, por supuesto, vaciar los contenidos éticos sino lograr distinguir entre las pretensiones de universalidad de una tradición moral particular y el pluralismo ético que caracteriza las prácticas e identidades sexuales y reproductivas de la ciudadanía.

La política de estos movimientos volvió visible las formas en que lo religioso funciona como un basamento, "bajo relieve" (Montero, 2009) o "residuo reprimido" (Sullivan et al., 2011) en el derecho secular. Como parte de este proceso comenzaron a legitimarse nuevos derechos y políticas públicas vinculados a las formas de regular el parentesco, la reproducción o la sexualidad (entre otras) que son antitéticas con la sostenida por la tradición católica. Estos nuevos derechos y políticas públicas son críticos de una concepción biologizante, naturalista, de la sexualidad y también de las jerarquizaciones y relaciones de poder que dicha concepción enmascara a través de asumir la complementariedad entre hombres y mujeres (ambas dimensiones que aún defiende la Iglesia Católica). No solo está en juego un conjunto de regulaciones legales sino la función simbólica del derecho como jerarquizador de una moral sexual basada en el matrimonio y la sexualidad reproductivista. Los movimientos feministas y LGBTQI además de desnaturalizar las construcciones sobre las que se sostiene el heteropatricarcado, también "desnaturalizan" el derecho desconectándolo de concepciones morales universalizantes.

Estas críticas (obviamente junto a otras) permitieron que la perspectiva de género fuera ganando espacio político y legal. Para ello fue relevante el trabajo de distintxs profesionales y operadorxs del derecho. Entre ellxs se destacan los profesorxs de derecho que incorporaron lecturas y debates feministas y pro diversidad sexual en facultades que raramente estimulan el pensamiento crítico. Cualquiera que haya transitado sus aulas, tendrá sobrados ejemplos (incluso violentos) de las formas en que la enseñanza del derecho favorece su basamento moralizante y misógino. La estructura jerárquica de las cátedras deja en manos de lxs profesorxs titulares (en general hombres) el contenido de los programas que suelen mantenerse inalterables a través de las décadas. A ello se suma que la gran mayoría de los profesorxs son funcionarixs judiciales o abogadxs litigantes que tienden a reproducir en las clases un formalismo jurídico que, en general, es acrítico del papel del derecho en la estructuración de las desigualdades.

Estxs profesorxs al incorporar lecturas vinculadas al género y la sexualidad lograron agujerear el campo de la enseñanza del derecho. Las materias "menos jurídicas" (como 
sociología, filosofía o ciencias políticas) fueron en un principio más proclives a una mirada crítica del derecho y sirvieron de puente para la llegada de las perspectivas feministas y pro diversidad sexual en las facultades de derecho. Pero también algunxs profesorxs comenzaron a incluir bibliografía (nacional e internacional) que tensionaba las llamadas materias codificadas desde estas perspectivas. Incluso materias como el derecho público o el penal, que se caracterizan por la marginación de las (pocas) mujeres especialistas en el área, comenzaron a reflexionar críticamente sobre su rol en la institucionalización de un régimen hetero-patriarcal. En la actualidad, podría afirmarse, no hay área del derecho que haya quedado excluida de las críticas feministas, aunque un importante sector del profesorado las siga ignorando.

La perspectiva de género también fue impulsada por el trabajo profesional de abogadxs patrocinando mujeres y personas sexo disidentes. El uso del poder judicial ha sido crucial en la interrupción de la hegemonía conservadora de las políticas estatales y posterior desmantelamiento. En algunas circunstancias, esta judicialización fue parte de las estrategias de los movimientos con el propósito de lograr cambios legales en el parlamento. Por ejemplo, leyes innovadoras como el matrimonio para las parejas del mismo sexo (2010) o la de identidad de género (2012) fueron precedidas por fallos que aportaron antecedentes y argumentos para su debate y sanción. En otras circunstancias, abogadxs motivadxs por casos puntuales encuentran en el feminismo jurídico opciones y argumentos que les permiten correr las fronteras existentes en la interpretación del derecho. Una mención especial merecen lxs profesionales que llevaron estas defensas en provincias que se caracterizan por un mayor poder político de la jerarquía católica y sectores aliados. En estas circunstancias fue importante la emergencia de una capilaridad feminista y LGBTQI que traspasa la noción convencional de un movimiento social y sirve de soporte a estxs profesionales intercambiando escritos judiciales, argumentos legales o bibliografía.

Estos procesos de judicialización implican un notable esfuerzo para lxs profesionales del derecho que suele pasar inadvertido. Les requiere traducir las heterogéneas demandas de los movimientos en términos del lenguaje técnico y de las formalidades del campo jurídico. En este proceso de juridificación, siempre complejo e inestable, lxs abogadxs tuvieron que romper el tecnicismo que suele usarse (como marcador de distancia y poder con el cliente) para lograr una mayor horizontalidad con los movimientos. No solo tradujeron las demandas de los movimientos al lenguaje técnico, sino que también potenciaron las habilidades de los activismos para argumentar jurídicamente. El hiato (siempre presente) entre la radicalidad de las demandas políticas y su traslación en términos legales se convirtió en una zona de constante desafío y creatividad.

El papel de estxs profesionales del derecho (junto a otrxs actorxs) permitió que la perspectiva de género hendiera las políticas del Estado. En relativamente poco tiempo (y con sus limitaciones) esta perspectiva adquirió una centralidad relevante en las discusiones y formulaciones del derecho y las políticas públicas. Esta centralidad, como proponemos a continuación, ha implicado sin embargo una serie de tensiones y desafíos.

\section{Desafíos y tensiones}

Salir de los márgenes de la política y lograr el estatus de perspectiva legitimada trae aparejados desafíos, algunos de los cuales provienen de la heterogeneidad misma de los movimientos feministas, LGTQI y sus demandas. Estos movimientos ocuparon por décadas un lugar periférico en las tomas de decisiones y llegaron, en relativamente poco tiempo, a impactar, o incluso a ser parte de los poderes del Estado. Este paso 
(parcial, relativo e inestable) de resistir el poder a ser parte del mismo, de activar en las calles a hacerlo desde las estructuras del Estado, trae aparejados, obviamente, nuevos riesgos. Entre ellos, el de esencializar el género, de reforzar una construcción homogénea (y homogeneizante) que no solo borra tensiones, sino que incluso refuerza fronteras excluyendo y priorizando algunos sectores y/o demandas sobre otros.

Un desafío en esta dirección es insistir en que la mayor presencia de las mujeres, como lo propone la reforma de la justicia, si bien central, no agota los cambios que requiere la perspectiva de género. La reforma judicial feminista, como nos vienen enseñando abogadas, profesoras y funcionarias, es mucho más que esto o, incluso, es otra cosa. Reformar el Poder Judicial requiere (entre otros aspectos) ampliar el acceso a la justicia, particularmente para aquellos sectores donde género y pobreza se potencian; proteger a las víctimas sin revictimizar y democratizar el lenguaje jurídico para hacerlo accesible. No solo se busca reformar al aparato burocrático, sino que, al hacerlo, se redefine la justicia desde paradigmas alternativos.

La institucionalización de la perspectiva de género vuelve más urgente rescatar su carácter plural y disidente ya que está constituida por un entramado de teorías y praxis muchas veces en conflicto. La juridificación de las demandas políticas, si bien necesaria, corre el riesgo de aplanar esta complejidad y borrar los conflictos. Esto requiere de una sospecha sobre las propias categorías, género incluida, de una crítica constante a las implementaciones logradas. Estimular una insatisfacción política que empuje las formas institucionales (incluso las sentadas por nosotrxs mismxs). Una insatisfacción que no sea meramente cinismo o desconfianza hacia el derecho (instrumento indispensable en los conflictos políticos) sino que refleje una actitud crítica a su sacralización. Volver a formular las preguntas que nos permitieron visibilizar al heteropatriarcado pero, esta vez, orientadas hacia nuestras propias propuestas e instrumentaciones: ¿que grillas estamos construyendo en esta nueva legalidad? ¿Quiénes entran, cómo entran y quiénes no en ellas? ¿Qué definición de orden sexo-genérico se privilegia en las formulaciones legales y de políticas públicas?

Otro desafío que también obedece a la centralidad adquirida por la perspectiva de género se vincula a las reacciones y rearticulaciones conservadoras que, en algunos países, han llegado a revertir los cambios logrados. Es posible advertir el avance de una agenda política que considera a los movimientos feministas y LGBTQI como propulsores de una "ideología de género" que busca destruir la familia y el orden social a través de la utilización del Estado. Lejos de ser pura reactividad o rémora, estos sectores inscriben un proyecto político de recristianización que tiene al derecho y a las políticas públicas como arenas privilegiadas. Si bien miran hacia el pasado para restaurar un orden moral (nunca del todo vigente), lo proyectan hacia el futuro en tanto utopía reaccionaria (Traverso, 2018) o, podría decirse, como fantasía restaurativa.

Estas rearticulaciones conservadoras han evidenciado su capacidad de impacto en distintas arenas. El haber fisurado la hegemonía conservadora no significa haber superado la capacidad de influencia de operadorxs conservadorxs sobre el campo jurídico. Al contrario, la legitimación de la perspectiva de género implicó una reacción de sectores que buscan recuperar la influencia perdida en la sanción e interpretación del derecho. Si bien esta juridificación reactiva utiliza recursos y actorxs preexistentes, ensaya también nuevas alianzas y argumentos técnicos. Uno de los desplazamientos argumentales que ha adquirido presencia en distintos contextos es la defensa de la libertad como forma de oponerse a los derechos sexuales y reproductivos (Brown, 2019). Los ataques a la perspectiva de género se basan en la defensa de la libertad religiosa, de la libertad de conciencia, de la libertad de asociación, de la libertad familiar (entre otros constructos que circulan en los debates legales). 
La lucha contra la perspectiva de género es también parte de programas electorales y de gobierno, con notable éxito en algunos contextos. Las reacciones al avance de los movimientos feministas y LGTBQI han potenciado dos maneras de canalizar el conservadurismo moral en la política regional. Por un lado, la creciente presencia de partidos y candidatxs confesionales que movilizan (nuevamente) lo religioso como una dimensión en la discusión del derecho y las políticas públicas. Sin desconocer que las religiones han impactado históricamente en los sistemas partidarios, el avance de los derechos sexuales y reproductivos intensificó la ciudadanización de lo religioso en la sociedad civil y política (Vaggione, 2107). Por otro lado, los partidos y propuestas de derecha han incorporado en sus plataformas la lucha contra la "ideología de género" como una forma de resistir lo que consideran un avance regional de la izquierda. La tradicional alianza entre partidos de derecha y conservadurismo moral ha dado lugar a renovadas articulaciones entre el neoconservadurismo y el neoliberalismo que abrevan en la lucha contra la "ideología de género" como un objetivo compartido.

La perspectiva de género atraviesa, entonces, un doble desafío. Por un lado, se vuelve necesario reforzar la crítica sobre los logros alcanzados; no perder la capacidad revulsiva de los movimientos feministas y LGBTQI incluso (o más aun) cuando algunas de sus demandas se vuelven políticas estatales. Es necesario, paradójicamente, preservar la capacidad de resistencia al poder siendo parte, incluso, del mismo. Por otro lado, la derechización política que caracteriza a la mayoría de los países de la región tiene como uno de sus metas recristianizar la sociedad a través de las políticas estatales. Para ello, la lucha contra la perspectiva de género, rotulada como "ideología de género", permite alianzas y argumentos renovados contra la vigencia de los derechos sexuales y reproductivos. De la resolución de estos desafíos que tensionan la perspectiva de género desde lugares distintos, incluso opuestos, depende en gran medida no solo la libertad sexual y reproductiva sino la calidad misma del sistema democrático. 


\section{Q Bibliografía}

» Beaman, L. (2013). The Will to Religion: Obligatory Religious Citizenship. Critical Research on Religion, vol. 1, № 2: 141-157.

"Brown, W. (2019). In the ruins of neoliberalism: the rise of antidemocratic politics in the West. Nueva York, Columbia University Press.

» Jakobsen, J. R. y Pellegrini, A. (2004). Love the Sin. Sexual Regulation and the Limits of Religious Tolerance. Boston, Beacon.

» Montero, P. (2009). Secularização e espaço público: a reinvenção do pluralismo religioso no Brasil. Etnográfica, vol. 13 (1): 7-16.

» Sullivan, W. F.; Taussig-Rubbo, M. y Yelle, R. A. (2011).. Introduction. En After Secular Law. Stanford, Stanford University Press.

»Traverso, E. (2018). Las nuevas caras de la derecha. Buenos Aires, Siglo XXI.

"Vaggione, J. M. (2017). La Iglesia Católica frente a la política sexual: la configuración de una ciudadanía religiosa. Cadernos Pagu. Campinas, № 50. 